\title{
Pengaruh Suhu terhadap Perkembangan Pradewasa Parasitoid Eriborus argenteopilosus Cameron (Hymenoptera: Ichneumonidae)
}

\author{
Novri Nelly ${ }^{1 *}$, Trimurti Habazar1), Rahmat Syahni ${ }^{1)}$, dan Damayanti Buchori²) \\ 1)Fakultas Pertanian, Universitas Andalas, Padang 25163 \\ 2)Departemen Proteksi Tanaman, Fakultas Pertanian, Institut Pertanian Bogor, Bogor 16680 \\ Diterima 12-03-2009 Disetujui 05-11-2009
}

\begin{abstract}
ABSTRAK
Temperature effect on development time of the preadult parasitoid Eriborus argenteopilosus Cameron (Hymenoptera: Ichneumonidae) were studied to know development time, degree days and survival rate. Crocidolomia pavonana (Fabricius)(Lepidoptera: Pyralidae) larvae was exposed to E. argenteopilosus female and reared at four different temperatures i.e $16^{\circ} \mathrm{C}, 20^{\circ} \mathrm{C}, 25^{\circ} \mathrm{C}$ and $30^{\circ} \mathrm{C}$. Data were analyzed using anova and linear regression to calculate degree day. At $20^{\circ} \mathrm{C}$ E. argenteopilosus showed the highest degree day and survival rate $(18.67 \%)$, while at $30^{\circ} \mathrm{C}$ nothing adult parasitoid emergenced. Degree day to development time of parasitoid at temperature $20^{\circ} \mathrm{C}$ i.e fase egg-adult: 300.05; egg-pupae 173.35; pupae-adult 171.
\end{abstract}

Keywords: Parasitoid E. argenteopilosus, Preadult development, Temperature

\section{PENDAHULUAN}

Diantara faktor lingkungan abiotik, suhu berperan penting dan mempengaruhi keberadaan dan kehidupan suatu parasitoid (Madar \& Miller, (1983), Uckan \& Ergin, (2003). Beberapa penelitian tentang pengaruh suhu terhadap kebugaran parasitoid telah dilakukan, antara lain oleh Lauzierre et al., (2002), yang meneliti mengenai pengaruh suhu yang berbeda dengan kelembaban konstan, terhadap lama perkembangan Lydella jalisco (Woodley) (Diptera: Tachinidae) parasitoid pada Eoreuma loftini (Dyar) (Lepidoptera: Pyralidae). Hasil penelitian menunjukkan bahwa semakin tinggi suhu maka perkembangan parasitoid ini semakin cepat. Suhu pemeliharaan $35^{\circ} \mathrm{C}$ menyebabkan lama perkembangan akan cepat dibandingkan dengan suhu yang lebih rendah. Pada suhu $20^{\circ} \mathrm{C}$ jumlah imago yang muncul mencapai $62,5 \%$, dan hanya $9,5 \%$ pada suhu $35^{\circ} \mathrm{C}$. Ambang suhu terendah atau batas terendah parasitoid masih bisa berkembang, untuk fase larva $L$. jalisco adalah $14,5^{\circ} \mathrm{C}$ dan pupa $13,8^{\circ} \mathrm{C}$. Urbaneja et al., (2002), juga telah meneliti pengaruh suhu terhadap lama hidup Cirropilus vititotus Walker (Hymenoptera: Eleupodidae) ekto parasitoid pada Phyllocnistis citrulaliStainton (Lepidoptera: Gracillalidae), dan melaporkan bahwa siklus hidup parasitoid ini adalah 36,58 hari pada suhu $15^{\circ} \mathrm{C}$ dan hanya 14,60 hari jika dipelihara pada suhu $35^{\circ} \mathrm{C}$. Selanjutnya Almeida et al., (2002), melaporkan suhu optimal untuk pemeliharaan parasitoid Tachinaephagus zealandicus Ashmead (Hymenoptera: Encyrtidae) adalah $22^{\circ} \mathrm{C}$, yang ditandai dengan jumlah imago paling banyak muncul (100\%) dibandingkan suhu $16^{\circ} \mathrm{C}$ $(30,4 \%)$ dan $25^{\circ} \mathrm{C}(35 \%)$.

Pengamatan siklus hidup parasitoid pada beberapa suhu konstan dapat menentukan jumlah panas atau derajat hari yang dibutuhkan parasitoid tersebut untuk tiap fase pertumbuhannya. Penghitungan derajat hari (Degree day) merupakan suatu hal yang penting untuk menentukan dan meramal lama perkembangan serangga secara umum dan parasitoid khususnya. Derajat hari yang dibutuhkan untuk perkembangan parasitoid pada suhu tertentu akan berbeda untuk tiap fase pertumbuhannya. Hasil penelitian Seal et al., (2002), menyatakan derajat hari untuk pertumbuhan Catolaccus hunteri Crawford (Hymenoptera: Pteromalidae) parasitoid Anthonomus eugenii Cano (Curculionidae: Coleoptera) berbeda pada setiap fase pertumbuhannya. Jumlah derajat hari tertinggi pada fase telur dan pupa adalah pada suhu $30^{\circ} \mathrm{C}$ dibandingkan 20 dan $25^{\circ} \mathrm{C}$, Sedangkan fase prapupa dan larva derajat hari pada suhu $20^{\circ} \mathrm{C}$ lebih tinggi dibanding suhu 25 dan $30^{\circ} \mathrm{C}$.

\footnotetext{
*Telp: +6281374689271

Email: novrinelly@yahoo.com
} 
Eriborus argenteopilosus adalah parasitoid yang berpotensi sebagai agens pengendali hayati, karena selain menyerang $C$. pavonana parasitoid ini juga mampu menyerang beberapa jenis hama lainnya, seperti Spodoptera litura Fab (Lepidoptera: Noctuidae) dan Helicoverpa armigera Fab (Lepidoptera: Noctuidae) (Kalshoven, 1981). Tingkat parasitisasi parasitoid ini pada C. pavonana di laboratorium tergolong tinggi yaitu $78,96-87,00 \%$, dengan tingkat keberhasilan hidupnya $11-17 \%$ (Sahari, 1999). Untuk meningkatkan keberhasilan hidup suatu parasitoid maka perlu dipelajari aspek yang mempengaruhi kehidupannya. Sampai sejauh ini aspek suhu yang sangat mempengaruhi kehidupan parasitoid $E$. argenteopilous belum banyak dilaporkan. Informasi tentang suhu sangat penting sebagai syarat dasar ekologi untuk pengembangan $E$. argenteopilosus. Penelitian ini bertujuan untuk mempelajari pengaruh suhu terhadap pertumbuhan pradewasa, derajat hari dan sintasan parasitoid Eriborus argenteopilosus.

\section{BAHAN DAN METODE}

Perbanyakan serangga inang $C$. pavonana. Larva inang $C$. pavonana dikoleksi dari pertanaman kubis di daerah Cibodas, Jawa Barat. Larva tersebut dibiakkan di laboratorium dalam kotak plastik pemeliharaan berukuran $35 \times 27 \times 7 \mathrm{~cm}$. Pada dasar kotak diberi alas kertas stensil dan diberi daun kubis sebagai pakan larva. Ketika larva sudah instar empat, diberi serbuk gergaji untuk tempat berpupa. Semua imago jantan dan betina yang muncul dari pupa dipelihara dalam kurungan kain kasa berbingkai kayu berukuran $50 \times 50 \times 50 \mathrm{~cm}$. Imago tersebut diberi pakan larutan madu 10\% (madu:air $=1: 9 \mathrm{v} / \mathrm{v}$ ) yang diserapkan pada segumpal kapas dan digantung dalam kurungan. Untuk tempat peletakan telur bagi imago dimasukkan daun kubis ke dalam kurungan tersebut. Telur dipanen setiap hari dan disimpan dalam cawan petri sampai menetas. Larva instar dua siap dijadikan inang untuk percobaan.

Persiapan parasitoid E. argenteopilosus. Parasitoid E. argenteopilosus dikoleksi dari tempat yang sama dengan asal inangnya. Imago parasitoid di lapangan ditangkap dengan menggunakan jaring serangga, dan dipelihara di laboratorium dalam kurungan plastik berbentuk tabung (tinggi $23 \mathrm{~cm}$, diameter $12 \mathrm{~cm}$ ). Sebagai pakan diberikan larutan madu 10\%. Untuk perbanyakan parasitoid, larva inang dipaparkan pada parasitoid selama 24 jam. Inang itu dipelihara dalam wadah plastik (diameter $10 \mathrm{~cm}$ dan tinggi $12 \mathrm{~cm}$ ) sampai pupa parasitoid terbentuk. Pupa parasitoid tersebut kemudian dikumpulkan dalam kurungan plastik (tinggi $27 \mathrm{~cm}$, diameter $12 \mathrm{~cm}$ ) sampai imago muncul. Imago betina yang muncul digunakan untuk percobaan atau untuk perbanyakan berikutnya. Pupa parasitoid juga dikoleksi langsung dari larva $C$. pavonana yang dikumpulkan dari lapangan dan dipelihara dilaboratorium. Imago yang muncul dari pupa tersebut juga digunakan langsung untuk percobaan.

Pengaruh suhu terhadap perkembangan pradewasa E. argenteopilosus. Penelitian menggunakan rancangan acak lengkap (RAL) dengan 4 perlakuan dan 10 ulangan. Perlakuan terdiri dari pemeliharaan pradewasa parasitoid pada suhu yang berbeda yaitu $16,20,25$, dan $30^{\circ} \mathrm{C}$. Setiap unit perlakuan terdiri atas 30 larva inang terparasit.

Satu ekor imago betina $E$. argenteopilosus yang telah berumur 2-5 hari dan telah berkopulasi dimasukkan ke dalam tabung reaksi, kemudian diberi 3 larva $C$. pavonana instar 2 lebih kurang 3 menit atau sampai parasitoid selesai menusukkan ovipositornya pada larva tersebut. Setiap larva yang telah terparasit dikeluarkan dan dimasukkan ke dalam wadah plastik (diameter 10 $\mathrm{cm}$ dan tinggi $12 \mathrm{~cm}$ ) sampai mencapai. Larva inang terparasit sebanyak 30 larva dimasukkan ke dalam masing masing wadah plastik, sebelumnya diberi alas dengan kertas tissu dan dimasukkan daun kubis sebagai pakan. Wadah tersebut dimasukan ke dalam inkubator (tipe $250 \mathrm{MRL}$ ) dengan suhu sesuai perlakuan. Pakan larva inang diganti setiap hari, sampai terbentuk pupa. Pengamatan pradewasa dilakukan pada larva inang terparasit karena parasitoid $E$. argenteopilosus bersifat endoparasitoid.

Pengamatan dilakukan terhadap: (1) Lama pertumbuhan $(D T=$ development time), derajat hari ( $D D=$ Degree Day) pradewasa E. argenteopilosus (hari) ditentukan berdasarkan total lama stadia telur-pupa dan lama stadia pupa-imago. (2) Sintasan; adalah perbandingan jumlah pradewasa yang masih bertahan hidup dengan jumlah larva inang terparasit. (3) Jumlah pupa dan persentase imago parasitoid yang muncul serta nisbah kelamin. Jumlah pupa parasitoid yang terbentuk ditentukan berdasarkan total jumlah pupa parasitoid yang terbentuk, dan persentase imago yang muncul dihitung berdasarkan jumlah imago yang muncul dibandingkan dengan total larva inang terparasit x $100 \%$. 
Nisbah kelamin ditentukan berdasarkan perbandingan imago parasitoid jantan dan betina yang muncul.

Analisis data. Data pengamatan dianalisis dengan ANOVA menggunakan program STATISTIX 8,0 dan dilanjutkan dengan uji Tukey pada taraf nyata $5 \%$. Laju pertumbuhan ( $D R=$ Development rate) masing masing stadia dihitung dengan cara Lauziere (2002), sebagai berikut:

$\mathrm{DR}=1 / \mathrm{DT}$

$\mathrm{DR}=$ laju pertumbuhan.

$\mathrm{DT}=$ lama pertumbuhan

Untuk menentukan ambang suhu terendah tiap fase pertumbuhan parasitoid ditentukan dengan analisis regresi antara laju pertumbuhan dan suhu. Ambang pertumbuhan terendah yaitu suhu yang menyebabkan tidak terjadi pertumbuhan parasitoid atau laju pertumbuhan $(D R)=0$, untuk perkembangan fase telur-pupa, pupa- imago dan telur-imago diduga dengan menggunakan regresi dari laju pertumbuhan, dengan rumus (Lauziere, 2002):

$Y=a+b X$

$Y=$ laju pertumbuhan (DR),

$\mathrm{a}$ dan $\mathrm{b}=$ konstanta

$X=$ suhu dalam derajat celcius

$Y_{0}=T_{0}$ yaitu titik potong pada sumbu $Y$ saat $D R=0$.

Untuk tingkat perkembangan parasitoid yang dipelihara pada suhu yang berbeda, dihitung unit suhu harian atau derajat hari (degree day $=D D$ ) yang dibutuhkan untuk perkembangan tiap fase. Derajat hari ditentukan dengan menggunakan rumus berikut (Lauziere, 2002):
$\mathrm{DD}=\mathrm{d}\left(\mathrm{T}-\mathrm{T}_{0}\right)$

$\mathrm{DD}=$ derajat hari

$\mathrm{d}=$ rata rata lama pertumbuhan (hari) pada temperatur $\mathrm{T}\left({ }^{\circ} \mathrm{C}\right)$ atau suhu masing masing perlakuan

$\mathrm{T}_{0}=$ ambang suhu terendah; yaitu suhu pada saat tidak ada pertumbuhan, $\mathrm{DR}=0$ atau $\mathrm{Y}=0$.

\section{HASIL DAN PEMBAHASAN}

Pengaruh suhu terhadap perkembangan pradewasa E. Argenteopilosus. Hasil penelitian menunjukkan bahwa suhu sangat mempengaruhi lama dan laju perkembangan E. argenteopilosus. Semua perlakuan suhu berpengaruh sangat nyata $(P=0,000)$ pada setiap fase perkembangan parasitoid ini, kecuali untuk laju perkembangan pada fase pupa-imago $P=0,060)$ (Tabel 1).

Pertumbuhan parasitoid pradewasa $E$. argenteopilosus dari fase telur-pupa, pupa-imago dan telur-imago terjadi pada suhu 16,20 dan $25^{\circ} \mathrm{C}$, sedangkan pada suhu $30^{\circ} \mathrm{C}$ tidak ada satupun imago yang muncul. Telur yang diletakkan E. argenteopilosus pada larva inang yang dipelihara pada suhu $30^{\circ} \mathrm{C}$ hanya berkembang sampai pupa.

Semakin tinggi suhu maka perkembangan pradewasa parasitoid semakin cepat dan laju pertumbuhannya semakin tinggi. Jumlah unit suhu derajat hari $(D D)$ tiap-tiap perlakuan suhu juga tidak sama. Derajat hari tertinggi dari tiap fase perkembangan terjadi pada suhu $20^{\circ} \mathrm{C}$, yang ditentukan oleh lama dan ambang suhu terendah untuk perkembangan setiap fase.

Tabel 1. Rata rata lama pertumbuhan, laju pertumbuhan dan derajat hari untuk pradewasa parasitoid E. argenteopilosus pada suhu berbeda

\begin{tabular}{|c|c|c|c|}
\hline Suhu ${ }^{\circ} \mathrm{C}$ & Lmp $\pm s d$ (hari) & Ljp \pm sd(hari $\left.i^{-1}\right)$ & $\overline{\mathrm{DD}}$ \\
\hline \multicolumn{4}{|c|}{ Telur - pupa } \\
\hline 16 & $20,60 \pm 1,08 a$ & $0,05 \pm 0,00 a$ & 135,34 \\
\hline 20 & $16,40 \pm 0,70 \mathrm{~b}$ & $0,06 \pm 0,00 \mathrm{~b}$ & 173,33 \\
\hline 25 & $9,40 \pm 2,32 c$ & $0,11 \pm 0,03 c$ & 146,36 \\
\hline 30 & $7,30 \pm 1,60 d$ & $0,14 \pm 0,02 d$ & 150,16 \\
\hline \multicolumn{4}{|c|}{ Pupa - imago } \\
\hline 16 & $6,30 \pm 0,85 a$ & $0,16 \pm 0,02 a$ & 115,29 \\
\hline 20 & $7,70 \pm 0,85 a$ & $0,13 \pm 0,01 a$ & 171,92 \\
\hline 25 & $4,50 \pm 0,85 a b$ & $0,22 \pm 0,02 a b$ & 122,98 \\
\hline 30 & & & * \\
\hline \multicolumn{4}{|c|}{ Telur - imago } \\
\hline 16 & $26,90 \pm 1,24 a$ & $0,04 \pm 0,01 a$ & 227,31 \\
\hline 20 & $24,10 \pm 1,24 a$ & $0,04 \pm 0,01 a$ & 300,05 \\
\hline 25 & $13,90 \pm 1,24 b$ & $0,07 \pm 0,01 b$ & 282,56 \\
\hline 30 & & & , \\
\hline
\end{tabular}

Angka yang diikuti oleh huruf yang sama pada kolom yang sama pada masing- masing perlakuan tidak berbeda nyata dengan uji lanjut Tukey pada taraf nyata $5 \%$

Keterangan: $\mathrm{Lmp}=$ lama pertumbuhan (hari)

Ljp = laju pertumbuhan $\left(\right.$ hari $\left.^{-1}\right)$

* $\quad=$ tidak muncul imago parasitoid

$\mathrm{DD}=$ Degree Day

$\mathrm{Sd}=$ Standar deviasi 
Lama dan laju pertumbuhan serta derajat hari dari fase pupa - imago pada suhu $30^{\circ} \mathrm{C}$ tidak dapat dihitung karena tidak ada imago parasitoid yang muncul. Demikian juga derajat hari untuk fase pertumbuhan telur-imago parasitoid tidak bisa dihitung pada suhu tersebut. Pada suhu suhu $16-25^{\circ} \mathrm{C}$. Ambang suhu terendah untuk pertumbuhan parasitoid pada setiap fase ditentukan dengan membuat garis regresi linier dari grafik laju pertumbuhan (Gambar 1).

Hasil analisis regresi linier antara laju pertumbuhan parasitoid dan suhu, menunjukkan bahwa nilai $R^{2}$ dari

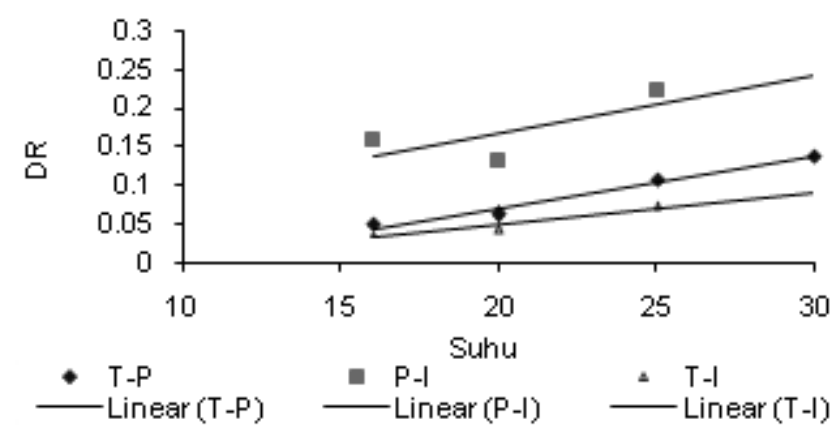

Gambar 1. Laju pertumbuhan pradewasa E. argenteopilosus pada suhu berbeda

Keterangan:DR = Development Rate. $(\mathrm{T}-\mathrm{P}=$ Telur $-\mathrm{Pupa})$, ( $\mathrm{P}-\mathrm{I}=$ Pupa- Imago), (T-I = Telur-Imago) persamaan regresi tiap fase pertumbuhannya berbeda nyata. Perbedaan dapat dilihat pada pertumbuhan telur sampai pupa dan pupa ke imago, demikian juga kalau dibandingkan dengan pertumbuhan mulai dari telur sampai imago (Tabel 2).

Ambang suhu terendah untuk pertumbuhan $E$. argenteopilosus dari telur - pupa adalah $9,43^{\circ} \mathrm{C}$, dari pupa- imago adalah $-2,33^{\circ} \mathrm{C}$, Sedangkan dari telur-imago adalah $7,55^{\circ} \mathrm{C}$. Derajat hari atau kumulatif suhu yang digunakan untuk pertumbuhan tiap fase juga berbeda pada setiap perbedaan suhu. Pada suhu $20^{\circ} \mathrm{C}$ adalah suhu dimana paling banyak jumlah imago parasitoid muncul, derajat harinya paling tinggi dibanding suhu lain pada tiap fase pertumbuhan.

Dalam pertumbuhannya larva inang yang telah terparasit tetap bertahan hidup, akan tetapi sintasan pradewasa parasitoid semakin lama semakin menurun (Gambar 2). Beberapa inang terparasit tetap bertahan sampai muncul imago parasitoid yaitu pada suhu 16, 20, dan $25^{\circ} \mathrm{C}$ (Tabel 3).

Persentase parasitoid yang jadi pupa dan imago yaitu berkisar antara 0-18,67\%, tertinggi adalah pada

Tabel 2. Persamaan regresi laju pertumbuhan (DR) dan ambang suhu terendah untuk pertumbuhan pradewasa E. argenteopilosus

\begin{tabular}{lccc}
\hline Laju pertumbuhan setiap fase & Persamaan Regresi & $R^{2}$ & $\begin{array}{c}\text { Ambang suhu terendah untuk pertumbuhan } \\
\left({ }^{\circ} \mathrm{C}\right)\end{array}$ \\
\hline Telur - pupa & $\mathrm{Y}=0,0067 \mathrm{x}-0,0632$ & 0,9765 & 9,43 \\
Pupa - imago & $\mathrm{Y}=0,0075 \mathrm{x}+0,0174$ & 0,5152 & $-2,33$ \\
Telur - imago & $\mathrm{Y}=0,0040 \mathrm{x}-0,0302$ & 0,8854 & 7,55 \\
\hline
\end{tabular}

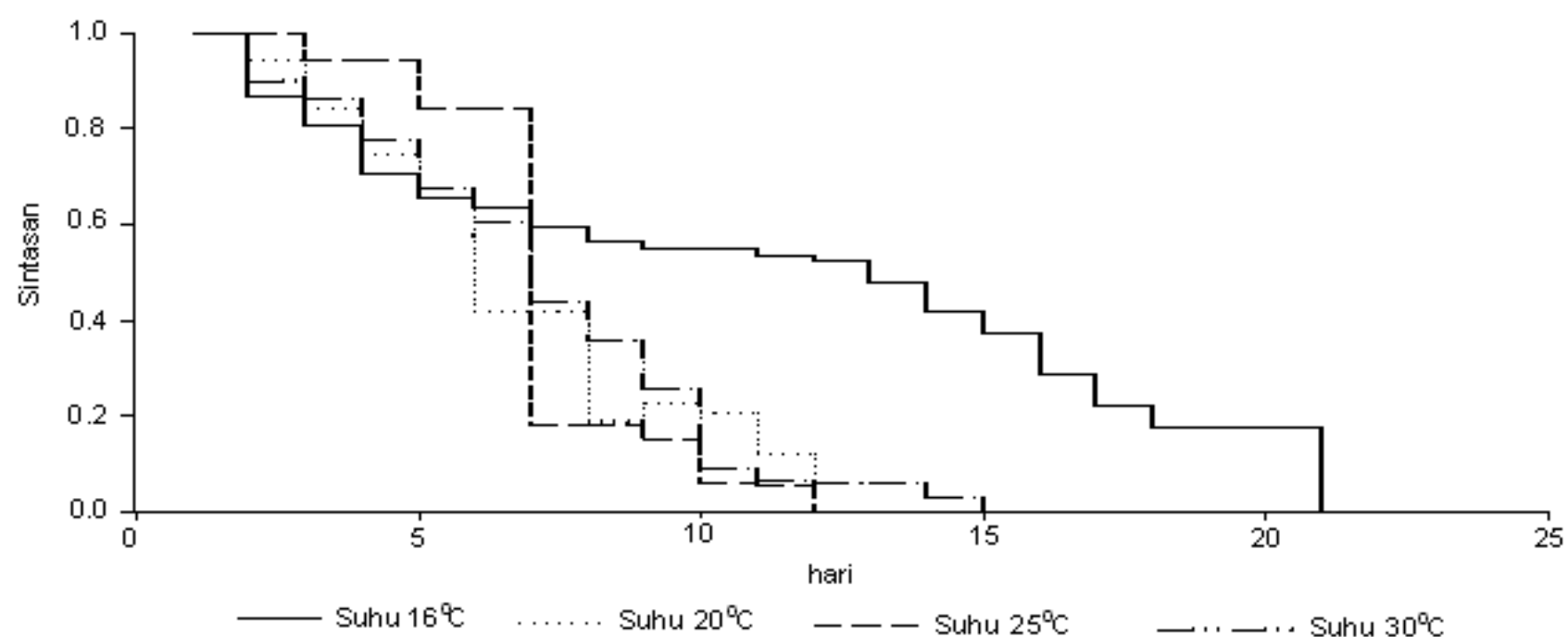

Gambar 2 Grafik laju sintasan pradewasa E. argenteopilosus dalam pemeliharaan pada suhu berbeda

Tabel 3. Jumlah pupa dan imago parasitoid E. argenteopilosus yang muncul pada suhu berbeda

\begin{tabular}{cccccc}
\hline Suhu $\left({ }^{\circ} \mathrm{C}\right)$ & Jumlah larva inang terparasit (ekor) & Jumlah pupa & \multicolumn{3}{c}{ Jumlah Imago yang muncul (ekor) } \\
\cline { 3 - 5 } & & & jantan & betina & \% \\
\hline 16 & 300 & 15 & 32 & 0 & 0,33 \\
20 & 300 & 68 & 1 & 0 & 18,67 \\
25 & 300 & 18 & 0 & 0,33 \\
30 & 300 & 6 & 0 & 0 & 0,00 \\
\hline
\end{tabular}


suhu $20^{\circ} \mathrm{C}$. Jumlah inang yang bertahan hidup setelah terparasit akan berkurang selama perkembangannya. Parasitoid karena bersifat koinobion, maka inang terparasit tetap bertahan hidup walaupun aktifitas makannya jadi berkurang. Pupa parasitoid terbentuk tapi dalam perkembangannya tidak menjadi imago karena terjadi gagal pupa, yaitu rumah pupa terbentuk akan tetapi larva tidak berkembang menjadi pupa. Jumlah imago betina terbanyak muncul dari pemeliharaan pada suhu $20^{\circ} \mathrm{C}$ dengan nisbah kelamin adalah 1,6:1.

Laju sintasan E. argenteopilosus semakin menurun selama waktu pemeliharaan. Sintasan pradewasa $E$. argenteopilosus pada suhu $16,20,25$, dan $30^{\circ} \mathrm{C}$ memperlihatkan selama waktu pemeliharaan jumlah yang bertahan hidup semakin menurun. Pradewasa yang dipelihara pada suhu yang lebih tinggi lebih cepat mengalami kematian dibandingkan suhu rendah, yang paling lama bertahan hidup terjadi pada suhu $16^{\circ} \mathrm{C}$.

Jumlah imago parasitoid yang muncul kebanyakan jantan, seperti pada suhu $25^{\circ} \mathrm{C}$. Imago E. argenteopilosus yang paling banyak muncul adalah dari suhu $20^{\circ} \mathrm{C}$ yaitu $18,67 \%$ dari total jumlah larva inang terparasit dengan jumlah jantan $10,67 \%$ dan betina hanya $8 \%$.

Keberhasilan pengendalian hayati dengan menggunakan parasitoid sangat dipengaruhi oleh iklim. Faktor iklim seperti; suhu, kelembaban, dan curah hujan adalah diantara faktor yang mempengaruhi kehidupan parasitoid. Studi tentang bioklimatik pada serangga inang dan parasitoid dapat menjelaskan penyebaran dan juga untuk melengkapi batasan kemampuannya secara fisiologis. Suhu yang sama antara tempat pengumpulan, perbanyakan dan kolonisasi dapat meningkatkan kesempatan untuk kesuksesan penyebaran parasitoid.

Proses pertumbuhan serangga secara umum sangat dipengaruhi oleh suhu. Demikian juga pada parasitoid E. argenteopilosus suhu berpengaruh terhadap lama perkembangan dan keberhasilan hidup. Lama pertumbuhan E. argenteopilosus untuk semua fase lebih pendek pada temperatur tinggi. Sama dengan hasil penelitian Chong et al., (2003), yang memperlihatkan bahwa pertumbuhan, sintasan dan keperidian Phenacoccus madeirensis Green (Hemiptera: Pseudococcidae) pada Chrysanthemum Dendrathema xgrandiflora Kitam, sangat dipengaruhi oleh suhu. Lama perkembangan pada suhu tinggi lebih cepat dibandingkan suhu rendah, sehingga laju pertumbuhannya meningkat.
Laju pertumbuhan E. argenteopilosus dari telur pupa dan pupa-imago akan meningkat dengan meningkatnya suhu. Peningkatan suhu mempercepat metabolisme dalam tubuh parasitoid sehingga pertumbuhannya lebih cepat. Pertumbuhan parasitoid yang cepat menyebabkan kebutuhan hidupnya dalam tubuh inang akan meningkat. Hal ini diduga yang menyebabkan mortalitas larva inang terparasit lebih cepat dengan meningkatnya suhu.

Suhu pemeliharaan yang paling banyak menghasilkan imago $E$. argenteopilosus dari larva inang C. pavonana terparasit adalah pada suhu $20^{\circ} \mathrm{C}$. Hal ini diduga karena adanya keseimbangan pertumbuhan antara parasitoid dengan inangnya pada suhu tersebut, sehingga inang tetap bertahan hidup dan parasitoid tetap berkembang. Selanjutnya pradewasa betina yang bertahan hidup juga lebih banyak pada suhu $20^{\circ} \mathrm{C}$, sehingga jumlah imago betina yang muncul juga banyak dibandingkan suhu 16,25 , dan $30^{\circ} \mathrm{C}$. Nisbah kelamin jantan dan betina E. Argenteopilosus pada suhu $20^{\circ} \mathrm{C}$ adalah 4:3. Dapat dikatakan bahwa suhu yang disarankan untuk melakukan perbanyakan parasitoid ini adalah $20^{\circ} \mathrm{C}$.

Perbedaan ambang suhu terendah untuk perkembangan E. argenteopilosus terjadi karena perbedaan lama pertumbuhan tiap-tiap fase yaitu dari telur-pupa dan telur-imago. Setiap fase pertumbuhan parasitoid diduga mempunyai suhu optimal yang berbeda. Menurut Lauziere et al., (2002), terdapat perbedaan suhu optimal untuk setiap fase pertumbuhan parasitoid. Suhu optimal untuk pertumbuhan larva $L$. jalisco yaitu $20-30^{\circ} \mathrm{C}$ dan $20-25^{\circ} \mathrm{C}$ untuk pupa, dengan ambang suhu terendah untuk larva adalah $12,6^{\circ} \mathrm{C}$ dan $14,3^{\circ} \mathrm{C}$ untuk pupa.

Derajat hari atau unit suhu harian yang dibutuhkan untuk pertumbuhan tiap fase pada suhu pemeliharaan pradewasa $E$. argenteopilosus antara $16-30^{\circ} \mathrm{C}$ juga tidak sama. Unit suhu harian tertinggi terjadi pada suhu $20^{\circ} \mathrm{C}$, pada fase telur-pupa adalah 184,758 sedangkan fase pupa -imago adalah 126,28 dan secara keseluruhan dari telur-imago 269,762 . Perbedaan jumlah derajat hari tiaptiap fase pertumbuhan $E$. argenteopilosus adalah akibat perbedaan lama dan laju pertumbuhan parasitoid ini pada suhu tertentu. Hasil penelitian Seal et al., (2002), memperlihatkan bahwa unit suhu harian untuk pertumbuhan larva dan prapupa Catolaccus hunteri Crawford (Hymenoptera: Pteromalidae) ektoparasitoid pada beberapa Coleoptera, famili Bruchidae dan 
Curculionidae akan meningkat pada suhu rendah. Unit suhu harian untuk perkembangan telur sampai pupa parasitoid ini paling tinggi pada suhu $30^{\circ} \mathrm{C}$. Dengan diketahuinya unit suhu harian untuk perkembangan, maka dapat dihitung lama perkembangan setiap fase pertumbuhan serangga.

Pupa E. argenteopilosus akan muncul pada akhir stadia larva $C$. pavonana, dengan kata lain inang tetap hidup dan tumbuh sampai larva instar akhir. Larva inang yang terparasit tetap melakukan aktifitas makan, akan tetapi kemampuan makannya lebih sedikit dibandingkan larva yang sehat atau tidak teraparasit. Hal ini sesuai dengan ciri parasitoid yang bersifat koinobiont, yaitu parasitoid tersebut tidak membunuh inang dengan cepat. Quicke (1997), menyatakan bahwa parasitoid yang bersifat koinobiont, inangnya tetap hidup dan tumbuh sampai fase tertentu dan terbentuk pupa parasitoid. Inang yang masih hidup ini tetap melakukan aktifitas makan akan tetapi sudah sangat berkurang dibanding yang tidak terparasit.

\section{KESIMPULAN}

Suhu berpengaruh terhadap pertumbuhan dan sintasan pradewasa parasitoid $E$. argenteopilosus pada larva inang $C$. pavonana. Suhu optimal untuk perkembangan parasitoid ini adalah $20^{\circ} \mathrm{C}$, dengan derajat hari atau Degree Day (DD) adalah 173,35 untuk telur-pupa, 171,94 untuk pupa-imago, dan telur-imago adalah 300,05

\section{UCAPAN TERIMA KASIH}

Terima kasih diucapkan kepada Direktur Yayasan PEKA Indonesia, Kepala Lab Bioekologi Predator dan Parasitoid Departemen Proteksi Faperta IPB Bogor yang telah memfasilitasi penelitian ini.

\section{DAFTAR PUSTAKA}

Almeida, M.A.F.D., Prado, A.P.D. \& Geden, C.J. 2002. Influence temperature on development time and longevity of Tachinaephagus zealandicus (Hymenoptera:Encyrtidae), and effects of nutrition and emergence order on longevity. Journal Environmental Entomology 31(2): 375-380.

Chong, J.H., Oetting, R.D. \&. lersel, M.W.V. 2003. Temperature effects on the development, survival, and reproduction of the madeira mealybug, Phenacoccus madeirensis (Hemiptera:Pseudococcidae), on chrysantemum. Annual Entomology Society American. 96(4): 530-533.

Kalshoven L.G.E. 1981. The Pest of Crop in Indonesia. Revised and Translated by P.A.van der Laan. PT. Ichtiar Baru-van Hoeve, Jakarta.

Lauziere, I., Setamou, M., Legaspi, J. \& Jones, W. 2002. Effect of temperature on life cycle of Lydella jalisco (Diptera: Tachinidae), a parasitoid of Eoreuma loftini (Lepidoptera: Pyralidae). Journal Environmental Entomology. 31(3): 432437.

Madar, R.J. \& Miller, J.C. 1983. Developmental biology of Apanteles yakutatensis (Hymenoptera:Brachonidae), a primary parasite of Autogrpha californica (Lepidoptera: Noctuidae) Annual Entomology Society American. 76: 683687.

Quicke, D.L.J. 1997. Parasitic Wasp; Chapman and Hall. London.

Sahari, B. 1999. Studi enkapsulasi parasitoid Eriborus argenteopilosus Cameron (Hymenoptera; Ichneumonidae) dan Implikasinya pada inang Crocidolomia binotalis Zeller (Lepidoptera: Pyralidae) dan Spodoptera litura Fabricius (Lepidoptera; Noctuidae). Skripsi. Institut Pertanian Bogor.

Seal, D.R., Stansly, P.A. \& Schuster, D.J. 2002. Influence of temperature and host on life history parameter of Catolaccus hunteri (Hymenoptera: Pteromalidae). Journal Environmental Entomology. 31(2): 354-360.

Uckan, F. \& Ergin, E. 2003. Temperature and food source effects on adult longevity of Apanteles galleriae Wilkinson (Hymenoptera: Braconidae). Journal Environmental Entomology 32(3): 441-446.

Urbaneja, A., Hinajeros, R., Llacer, E., Garrido, A. \& Jacas, J. A. 2002. Effect of Temperature on life history of Cirrospillus vittatus (Hymenoptera: Eulophidae), an Ectoparasitoid of Phyllocnistis citrella (Lepidoptera: Gracillariidae). Journal Economic Entomology 95 (2): 250253. 